\title{
Transformaciones agrarias y organización social en la Costa austral
}

\section{Agrarian transformations and social organization in the austral Coas}

\begin{abstract}
Germán Carrillo García ${ }^{1}$
gcarrillo@um.es

\section{Resumen}

A partir de la segunda mitad del siglo XX se iniciaban en Ecuador una serie de aceleradas transformaciones en todos los ámbitos. Las reformas agrarias de 1964 y 1973, en el marco de la "revolución verde", cambiaron los escenarios y los actores del mundo rural. La modernización del campo dejó atrás, en buena medida, el gamonalismo serrano y las aparcerías en la Costa, para ir adecuando las relaciones laborales y sociales al sistema capitalista. Las economías campesinas resintieron de un modelo de desarrollo ajeno a su racionalidad y pronto el campesinado, que había luchado por la tierra, conformó un nuevo proletariado rural en las modernas explotaciones agrícolas. Ciertos grupos de campesinos se mancomunaron en torno a cooperativas agrícolas, lo que de una u otra manera abriría posibilidades para su supervivencia. El estudio de caso de la organización campesina UROCAL (Unión Regional de Organizaciones Campesinas del Litoral) es representativo de los cambios aducidos en el mundo rural ecuatoriano, especialmente en la Costa austral del país.
\end{abstract}

\section{Palabras claves}

Ecuador, historia agraria, organización social, UROCAL.

\begin{abstract}
Since the second half of the 20th century, a series of quick transformations took place in Ecuador. Agrarian reform laws in 1964 and 1973, framed by the Green Revolution, changed the scenery and actors in the rural world. Modernization in the rural areas left gamonalismo (authoritative wealthy landownership) in the highlands and sharecropping in the coast, largely behind, in order to adapt labor and social relations to the capitalist system. Peasant economies resisted to a model of development that was alien to their rationality, and soon, the peasantry that had struggled for their land created a new rural proletariat within the modern agricultural farming backdrop. Some peasant groups united to form agricultural cooperatives that, in some way or another, would open their possibilities for survival. The study case of the peasant organization URO$C A L$ (Regional Union of Coastal Peasant Organizations) is representative of the alleged changes put forward in the rural world, particularly in the southern coast of Ecuador.
\end{abstract}

\section{Keywords}

Ecuador, agrarian history, social organization, UROCAL.

Forma sugerida de citar: CARRILLO GARCÍA, Germán (2013). “Transformaciones agrarias y organización social”. En: Universitas, XI (19), julio-diciembre, p. 181-216. Quito: Editorial Abya Yala/Universidad Politécnica Salesiana.

1 Profesor e investigador del Departamento de Sociología y Trabajo Social de la Universidad de Murcia. 


\section{Introducción}

El modelo de desarrollo agrícola implementado tras las sucesivas revoluciones verdes, desde la segunda mitad del siglo XX, está agotado. Las crisis de las sociedades contemporáneas tuvieron sus inicios, entre otras causas y por lo que aquí nos interesa, en la sobreexplotación de los recursos naturales y en la sobreestimación de un modelo de desarrollo económico creciente y lineal. Este rasgo definitorio no debería ser atribuido únicamente al sistema capitalista, sino a la culminación de las satisfacciones humanas en su sentido material por parte del "capitalista clásico" y del "rebelde de tradición marxista ortodoxa", que podrían "llevarnos a una catástrofe ecológica" (Thompson, 1995 en Tello, 2010).

Los estudios sobre las diversas formas de explotación agropecuarias y sus efectos derivados deben elucubrar un modelo de desarrollo que conjugue, armónicamente, cultivos orgánicos e industriales sustantivados por una investigación agronómica permanente, que priorice la sostenibilidad territorial. Pero no bastaría con ratificar nuevas formas de producción agropecuaria más sostenibles sino se transforma el imaginario colectivo emanado de "nuestra obsoleta mentalidad de mercado", a la que se refirió Karl Polanyi. Posicionamiento este último muy alejado de la preeminencia del economicismo neoconservador difundido cardinalmente a partir de 1973.

Las alarmas se disparaban tímidamente en 1972, cuando el Club de Roma emitía un primer informe bajo el significativo título Los límites del crecimiento. El modelo de desarrollo puesto en marcha por Occidente desde la primera revolución industrial, en la Inglaterra de 1750, así como el sistema de producción fordista iniciado el siglo XX, alzaba las voces de ciertos movimientos sociales en los años 60 bajo la denominación de "ecologistas"; empero, las autoridades políticas y las instituciones públicas y privadas dirigieron sus miradas hacia otro lado. Durante la década del 70 se fue pergeñando el entramado político neoliberal del mundo actual. Pocos años serían suficientes para que las instituciones surgidas de Bretton Woods, en coalición con las élites gubernamentales domésticas, iniciaran un proceso de encadenamiento de las economías latinoamericanas, haciéndolas dependientes de una financiación externa e incentivando su papel exportador, aduciendo que este rol -por otro lado ya viejo en Latinoamérica- desencadenaría toda una suerte de crecimiento económico. Sin 
embargo, los datos y los hechos pusieron de relieve todo lo contrario: la mayor parte de los países menos desarrollados mantenían una alta dependencia de la exportación sin una correlación precisa con el PIB por habitante.

Las reflexiones anteriores conducen al objetivo de este trabajo: exponer parte de los resultados generales de una investigación que analiza la problemática histórica, y por tanto, social, económica, cultural y política, derivada de los modelos de explotación agrícolas desarrollados en la Costa austral del Ecuador desde mediados del siglo pasado. ${ }^{2}$ Un trabajo de campo (2010) a partir de la exploración de una cooperativa agrícola, surgida en los convulsos años 70, con fuertes raíces en los 50 que fue el "decenio de prosperidad" (Cueva, 1983) en el Ecuador, delimitó el objeto de investigación y con él se fue develando la problemática derivada de los medios y las relaciones sociales de producción de los monocultivos, en expansión y crecimiento, sobre todo a partir de 1948, con el cultivo de banano. Dicha cooperativa denominada UROCAL (Unión Regional de Organizaciones Campesinas del Litoral) fue brindando una secuencia espacio-temporal comprensiva del territorio compuesto por microregiones de las provincias de Guayas, Azuay -principalmente en su parte costanera- y El Oro, en cuya capital, Machala, se halla la sede administrativa de la UROCAL.

2 "Historia agraria y organización social en la Costa austral de Ecuador, 1950-2010. Estudio de caso de una cooperativa agrícola: la Unión Regional de Organizaciones Campesinas del Litoral, UROCAL”. Este trabajo puede ser consultados en el Depósito Digital Institucional de la Universidad de Murcia (http://hdl.handle.net/10201/35409) y en FLACSO (http://hdl.handle.net/10469/5415). 
Figura 1

Ubicación de las asociaciones de UROCAL

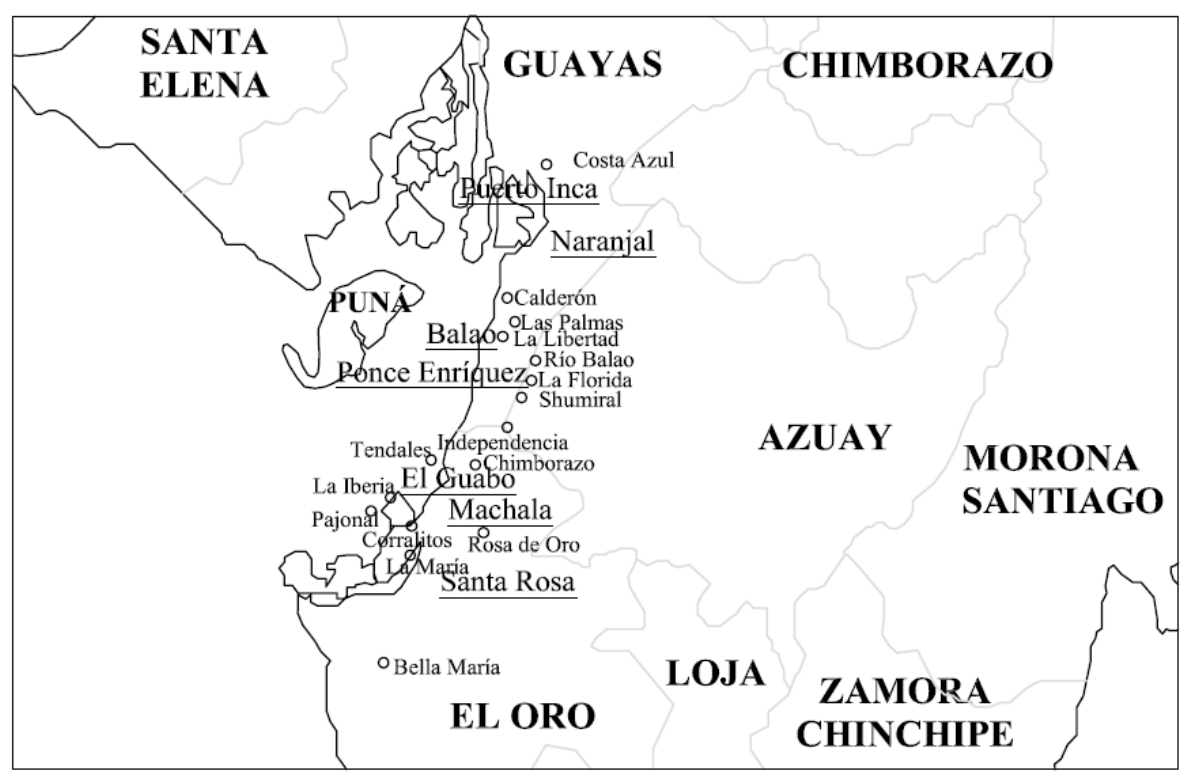

Fuente: el autor

Ecuador, como otros países de la región, ha formado parte del grupo de economías altamente dependientes de la agroexportación, particularmente de cacao y banano. Se sostiene como hipótesis general que las prácticas agropecuarias tradicionales tanto de base orgánica como industrial, sostenidas por una investigación permanente, desde un enfoque interdisciplinar superador del economicismo preeminente, pueden conformar la base estructural para el sostenimiento de la biodiversidad de los territorios. Sin embargo, esto anterior no es posible sin una estabilidad política reguladora del mercado. El marco cronológico abarcado por la investigación ofrece como resultados toda una serie de permanentes desequilibrios socioproductivos cuyos efectos sobre las pequeñas economías campesinas de la costa sur del Ecuador, han sido desfavorecedores para su sostenimiento, desestructurando a los campesinos, sus modos de 
vida, sus espacios culturales y relacionales. Sin embargo, los giros en la política agraria del último lustro en el país, podrían reconducir la situación de los agricultores dependientes de un mercado global excluyente. La historia de la organización agrícola UROCAL, contribuye a la comprensión de la reforma agraria, la agricultura orgánica, o las relaciones sociales de producción bajo forma cooperativista. No se ofrece en estas líneas un modelo ideal, sino un marco reflexivo a partir de un caso de estudio que, en nuestra opinión, puede contribuir a elevar el debate sobre la sostenibilidad territorial.

Cabe subrayar la escasa literatura científica que ha abordado la región costeña del Ecuador, en contrapartida con la ingente bibliografía sobre las comunidades indígenas situadas en los pisos altos de la Cordillera. Los registros bibliográficos se limitaban a varios estudios sectoriales del litoral, entre ellos podemos destacar los trabajos de John Uggen (1975), Martínez Valle (1976, 2003, 2013), Manuel Chiriboga (1978), Ibarra (1979), Silverman (1986), Guerrero (1979), Larrea (et al., 1988; Larrea, 1989), Striffler (1998, 2000, 2002).

\section{Territorios y actores, cambios y permanencias}

John Murra, en 1975, publicaba Formaciones económicas y políticas del mundo andino. El autor sostenía que las relaciones sociales de la población indígena andina, se fundamentaban en el equilibrio de las potencialidades productivas propias de la verticalidad: a cada piso altitudinal le correspondía un nicho ecológico, y por tanto una variedad de cultivos, definiendo así el intercambio y abastecimiento comunitario. Cuando la demanda occidental de productos agrícolas revalorizó las tierras de América Latina, desde aproximadamente 1870, las poblaciones andinas fueron sometidas por un puñado de criollos a partir de los sistemas de explotación derivados de la hacienda serrana y la plantación costeña (Pachano, 1988: 393 en Chiriboga, 1988). De esta manera se abandonaba, forzosamente, la agricultura tradicional de intercambio, y se iniciaba un proceso de dominación sobre los indígenas, ejercido por los gamonales o señores de las haciendas, donde mantenían sus dominios bajo un "régimen de semi-esclavitud", conocido como el huasipunaje, extendido por toda la Sierra Andina (Marchena, 2006: 33-34). 
En las tierras del litoral, se conformaba una clase social de grandes propietarios que Andrés Guerrero dio en calificar, acertadamente, como los "oligarcas del cacao" (Guerrero, 1981), pues se trataba de una clase de terratenientes cuyos patrimonios se concentraban en unas veinte familias: "los Aspiazu llegaron a tener en propiedad 59 haciendas, quizás 180.000 hectáreas; los Seminarios, llamados Reyes del Cacao, 35 haciendas con unas 150.000 hectáreas; los Malo, Caamaño, Durán Ballén, Burgos, Puga, Rendón, Icaza, Avilez, tenían cada uno más de 10 grandes haciendas cacaoteras". Propiedades que se forjaron sobre la expropiación a pequeños agricultores, campesinos e indígenas, así como por la apropiación ilegal de tierras públicas. De esta manera, los antiguos propietarios terminarían convirtiéndose en jornaleros y sembradores de los nuevos dueños (Chiriboga y Piccino, 1981).

Las diferencias regionales, determinadas por la biodiversidad y edafología definirían así, históricamente, tres grandes regiones en el Ecuador: la Sierra, Costa y Amazonía. Principalmente en la región costeña, formada por las provincias, de norte a sur, de Esmeraldas, Manabí, Los Ríos, Guayas, Santa Elena y El Oro, estuvo sometida a cultivos extensivos de cacao desde mediados del siglo XIX. A partir de la década de 1940, se iniciaba el cultivo de banano, impulsado durante la administración de Galo Plaza Lasso (1948-1952). La Costa conformó un territorio socioproductivo dirigido al mercado internacional desde fechas tempranas bajo el sistema de monocultivo. Sin embargo, en la Sierra, la producción se limitó a cubrir el mercado nacional y local inmediato a partir de cultivos de ciclo corto, tales como la papa, fréjol, maíz, cebolla, tomate, yuca, etc., como además destacó la ganadería, especialmente vacuna.

De esta forma, las relaciones sociales de producción en Ecuador se definían en cuanto a las demandas del mercado nacional e internacional. Y si, como hemos apuntado, la Costa proveía al mercado internacional, las relaciones sociales de producción fueron definiéndose eminentemente salariales o combinando el pago en salario y especie, incluso con anterioridad a las reformas agrarias.

Durante el periodo cacaotero se iría ampliando la frontera agrícola, restando arbolado al bosque tropical, proceso que aumentaría considerablemente con la expansión del cultivo de banano. Esto daría lugar a que la Costa fuera extendiendo sus bases demográficas, que de un tímido $15 \%$ en 1840 pasaría a un 47,5\% en 1962 (Larrea, 2005: 29). Durante la década de 1950, las provincias 
costeñas de Guayas, Los Ríos y El Oro recibieron el 80\% de las migraciones internas del país. Aunque estos movimientos migratorios fueron constantes desde finales del siglo XIX, aumentaron su volumen a partir del colapso del régimen hacendatario en la Sierra, sumado al inicio del cultivo de banano en la Costa; factores que indujeron la demanda de mano de obra en las plantaciones del litoral. Así quedaba reflejada la definición territorial por la que transcurrió la historia de la cooperativa UROCAL en la impronta de los archivos consultados:

Nuestra zona se ubica en la región costanera de las provincias del Azuay, sur del Guayas y norte del Oro; posee una gran riqueza en recursos de todo tipo por lo que ha sido controlada a través de grandes haciendas: hacienda Mollepongo, perteneciente a la familia Ordóñez, ubicada entre los ríos Jubones y Tenguel; hacienda Tenguel, propiedad desde los años treinta del siglo veinte de la multinacional United Fruit, ubicada entre el río Tenguel y Gala; por último la hacienda Pijili, propiedad de la familia Durán Oyervide entre los ríos Gala y Balao. Todas las haciendas recibieron a través de los tiempos oleadas migratorias desde la sierra y otros lugares, quienes fueron poblando [el territorio litoral] poco a poco. ${ }^{3}$

En buena medida, los campesinos desplazados del sector tradicional no pudieron reubicarse en las plantaciones de banano, esto provocó a su vez una inquietud entre la clase dirigente del país ante posibles, y sobre todo, indeseados movimientos sociales. Sin duda la crisis de los años 60 era refractaria del decenio de prosperidad anterior; la década de 1950 supuso una "coyuntura económica favorable" no materializada en una "transformación estructural que asegurara la estabilidad duradera" (Cueva, 1983: 225-230). Se modernizarían las instituciones de Gobierno - como era de prever en un país que se incluía en la órbita capitalista internacional luego de la segunda guerra mundial-, como también se fomentaría la inversión pública y privada, la construcción de infraestructuras y redes viarias (Salgado, 2008: 120). Una vertebración regional adelantada medio siglo antes por el presidente liberal Eloy Alfaro (1897-1911). "El viejo luchador" llevó a cabo un conjunto de acciones dirigidas a vincular dinámicamente las regiones, entre las que destacaban la construcción del ferro-

3 Archivo Documental Centro de Educación y Capacitación del Campesinado del Azuay (en adelante: A. D. CECCA): UROCAL, V Congreso de la UROCAL, 1991. 
carril entre los dos principales polos urbanos: Guayaquil y Quito en 1908, y el inicio del proceso de articulación de la agroexportación capitalista costeña con la agricultura y producción artesanal manufacturera serrana. También se adoptaron medidas para avanzar en el poblamiento y suplir la demanda de mano de obra de la Costa, garantizando el flujo demográfico y laboral entre ambas regiones (Ojeda, 2000: 4-5).

Durante el mandato de Galo Plaza y el contexto favorable internacional de la segunda postguerra mundial, diversas empresas de la fruta tropical, principalmente la United Fruit Company, controlaban la comercialización de banano en la Costa, asumiendo la parte productiva empresas ecuatorianas, principalmente, a través de contratos (Ibarra, 2010[1979]). Este aspecto debiera haber favorecido la economía del país, pero exoneraba a la gran compañía de responsabilidades laborales; además, los salarios eran comparativamente con los pagados en Centroamérica un 40\% más bajos (Larrea, 2005: 42-45). El colapso del cultivo de cacao a partir de los años veinte, propició la entrada del banano como alternativa productiva. Sin embargo, la United Fruit, también operó directamente, "como dueña y administradora" en la conocida hacienda Tenguel, al sur de Guayaquil (Striffler, 2000: 155), cercana al caserío azuayo de Shumiral, donde germinó la UROCAL, como colonia agrícola hacia $1956 .{ }^{4}$

En resumen, la expansión del cultivo de banano por parte de las empresas, produjo una ampliación significativa de la frontera agrícola, con el subsiguiente derrumbe de bosque tropical; como además el uso de insumos sintéticos significó el deterioro sustancial de la riqueza y biodiversidad de las tierras costeñas. Sin embargo, el desmonte del bosque tropical, conviene recordar, se inició durante los procesos de colonización mencionados, cuando "los indios y pueblerinos bajaron a desmontar el bosque", en busca de tierras. Las prácticas de explotación agrícola de estos colonos, no siempre fueron sostenibles, de hecho estas familias de migrantes se "caracterizaron por una acción depredadora del bosque primario", en una búsqueda lógica por la autosubsistencia familiar (Martínez, 2003: 21-26). Si bien el contexto de modernización rural abierto

4 A. D. CECCA: "Los sucesos más conflictivos de la colonia agrícola Shumiral en la lucha por la tierra en los años 1958-1959". 
con las reformas agrarias a partir de $1964,{ }^{5}$ tuvo como objetivo primordial eliminar las prácticas latifundistas que provocaban tanto el agotamiento de las tierras andinas, como la deforestación masiva de la Costa (Jordán, 2003 en Vargas Vega, 2003), así como un sistema laboral precario; lo que devino fue la consolidación de una agricultura eminentemente mercantil dirigida al mercado internacional. La toma de tierras, efecto de la reforma, no contó con un apoyo estatal necesario para el sostenimiento de las fincas de los antiguos trabajadores de las plantaciones y haciendas. El campo se polarizaba, por un lado prevalecía el minifundio, y en el otro extremo, las propiedades capitalizadas fueron configurando el escenario costeño actual.

De esta manera, a finales de la década del 70, se agudizaba la precaria y difícil situación de las economías campesinas, se daba un proceso de reversión o acumulación de tierras tras un tímido ciclo reformista, asimétrico en los repartos de tierras entre finqueros y aparceros. Desaparecen, de esta manera, las diferencias entre Costa y Sierra, pues en la Sierra quedaban haciendas modernizadas y en la Costa se extendía la gran plantación moderna; en ambos casos crecía el proletariado y subproletariado agrícola. La Reforma Agraria promovió formas de tenencia de tierra comunitarias: cooperativas, asociaciones, colonias..., en orden a una mayor productividad, pero con un total fracaso debido a la falta de crédito, de asistencia técnica, de títulos de propiedad. ${ }^{6}$

\section{Reformas agrarias y revoluciones verdes}

¿Qué pretendía la reforma agraria? Una sola cosa, la penetración del capitalismo en el campo; es decir, la transformación de las haciendas en empresas agrícolas, mediante la transformación de los trabajadores precaristas en trabajadores asalariados o en productores directos ligados al mercado. Este objetivo se ha cumplido y por eso para el capital extranjero y sus sirvientes en este país, la reforma agraria está concluida, ya no se debe hablar de ella sino de "fomento

5 La primera Ley de Reforma Agraria y Colonización se sancionaba un 11 de julio de 1964, a través del Decreto 1480, bajo el Gobierno militar de Castro Gijón (1963-1966).

6 A. D. CECCA: "La Tierra”, 1986. 
agropecuario", de fomento de las empresas agropecuarias [...]. Este hecho, que parecía una conquista de los campesinos, solo significó el mecanismo a través del cual los latifundios trabajados bajo formas precarias pasan a producir para el mercado bajo formas más modernas, pues tan pronto como "conquistan" la tierra, las cooperativas se desintegran y la tierra se vuelve a reconcentrar, generalmente en manos de los dirigentes que ahora pasan a utilizar trabajadores asalariados. $^{7}$

La justificación ideológica de la revolución verde, en buena medida sustentada en la publicación de Elvin Charles Stakman y otros, en Campaigns against hunger (1967), ocultaba la trama histórica del programa geopolítico norteamericano para América Latina. Por un lado, se trataba de mostrar la eficacia de la tecnología agronómica norteamericana, como única vía hacia la modernización rural, con las ventajas de que esta evitaría revoluciones sociales y tendencias comunistas; y por otro, se abría un debate en torno a la "efectividad y pertinencia" de los programas de ayuda internacional impulsados por Estados Unidos. No obstante, como argumentaba Wilson Picado, el origen histórico de la "revolución verde" fue diluyéndose con el tiempo para cristalizar bajo el significado de "modernización agrícola", como vía para combatir la pobreza. Y sin embargo, como este autor mostraba, el mismo Henry Wallace, en 1941, publicaba una obra titulada ¿Qué hará Norteamérica?, donde se consignaba la idea subyacente de los programas ulteriores de ayuda y cooperación: "América Latina necesita la ayuda científica y económica de Norteamérica". Se sentaban así las bases del valor de la tierra en una doble acepción: "el valor del suelo como tierra de cultivo, y como tierra de ocupación geopolítica" (Picado, 2012: 110-112).

Los programas reformistas en la región durante las décadas del 60 y 70 se articulaban entre las políticas domésticas y los programas internacionales que las fueron impulsando. No se trataba tanto de promover una reforma agraria como de evitar conflictos sociales y políticos en un contexto histórico en el que el "espectro del socialismo", sobre todo a partir de 1959 con la revolución cubana, justificaba dichos programas y aceleraba el proceso de modernización e integración del campesinado en el sistema capitalista (Kay, 1995). En el caso

7 A. D. CECCA: I Congreso de la UROCAL, 1983. Archivo CECCA. 
ecuatoriano, resultaban esclarecedoras las palabras de un ministro del Gobierno de Ponce Enríquez (1956-1960): “existe la necesidad de entregar la tierra a quien desea cultivarla [...] si una reforma agraria no se hace a corto plazo, mediante un cambio del sistema legal puede ocurrir por revolución social [...] hay que procurar un cambio en el sistema actual de tenencia de la tierra, comenzando por aquellos bienes que pertenecen al Estado" (Barsky, 1984: 124-125).

La segunda Ley de Reforma Agraria, se sancionaba un 9 de octubre de 1973, por la junta militar presidida por Guillermo Rodríguez Lara (1972-1976). ${ }^{8}$ Bajo este nuevo marco legislativo se trataba, explícitamente, de llevar a cabo un proceso escalonado y planificado de la estructura agraria en sus aspectos económico, cultural, social y político, por medio de la afectación y redistribución de la tierra. Se subrayaba, además, la importancia de insumos tecnológicos, crédito, educación, salud, etc., cuyos fines debían ir dirigidos a la transformación de las condiciones de vida del campesinado y a la redistribución del ingreso agrícola. No obstante, se fue consolidando el minifundio, como en Bolivia o Perú, un sistema de explotación inviable económicamente en un contexto de liberalización progresiva de mercados para finales de la década de 1970.

Si bien las reformas agrarias debían ser contempladas dentro del marco geopolítico reseñado, la legislación agraria posterior, así como los programas de desarrollo rural impulsados en las décadas de 1980 y 1990, debían de enmarcarse en la sublimación progresiva de la agricultura tradicional al capitalismo agrario como única vía para modernizar los sistemas agrícolas de los países en vías de desarrollo. Efectivamente, como reza la cita introductoria de este acápite, las cooperativa surgidas de las reformas agrarias a tenor de la distribución y toma de haciendas, se diluyeron en gran medida, como consecuencia de la integración de los antiguos campesinos en el sistema mercantil, o más acertado sería afirmar, la imposibilidad de integrarse en el propio mercado: la ausencia de créditos, de asesoramiento técnico, las dificultades en la adquisición de insumos y de capital inversor, la concentración progresiva de tierras y el avance del minifundio, entre otros aspectos, ${ }^{9}$ provocó la transformación

8 Decreto N. 1172, publicado en el Registro Oficial N. 410 de 15 de octubre de 1973.

9 Como por ejemplo, "la inexistencia de un movimiento indígena de carácter nacional que presionara uniformemente por una demanda más amplia que la del huasipungo" (Jordán, 2003: 289). 
de estos campesinos propietarios en trabajadores asalariados. En el caso ecuatoriano, serían los antiguos hacendados y nuevos propietarios capitalistas los que modernizaron las explotaciones, y lograron su incorporación al mercado mundial en correlación con la progresiva decadencia de los pequeños e incluso medianos agricultores con tierras, que iban quedando excluidos de las nuevas relaciones mercantiles.

\section{Campesinos mancomunados}

No obstante lo anterior, de los causales de expropiación de la citada segunda Ley de Reforma Agraria de 1973 se beneficiarían campesinos mancomunados, como fue el caso de ciertas familias de agricultores del litoral que un año después de la sanción de dicha ley constituyeron, de derecho, la UROCAL. Cabe destacar algunos de los principales puntos de la ley que beneficiaron a la cooperativa:

a) Se considerará "acaparamiento de la tierra" [concepto que la Ley de 1964 no signaba en su articulado], si las fincas mayores de 200 ha aprovechables no tuvieren una productividad superior al $15 \%$ de promedio determinado por el Ministerio de Agricultura y Ganadería para el sector. Dicha superioridad deberá ser el $20 \%$ cuando la superficie aprovechable de la propiedad sobrepase de las 500 ha y el $25 \%$ si fuere superior a 1.000 ha. b) Predios mal cultivados; mal conservados desde el punto de vista medioambiental; no siendo mantenidos y gestionados directamente por el propietario.

De esta forma, se llevó a cabo la expropiación, reversión o extinción del derecho de dominio sobre la tierra, y así fue como los campesinos mancomunados a la UROCAL fueron adquiriendo predios para el cultivo de cacao, frutas, hortalizas y pastos. Aunque hay que señalar que las tierras que fueron afectadas $\mathrm{y}$ de las que se fueron apropiando las organizaciones campesinas, por norma general, constituyeron tierras improductivas, baldías o de difícil acceso a la finca, lo que dificultaba aún más la producción y su traslado fuera del predio.

Ante esta situación, los campesinos fueron formando cooperativas de base agregadas a la UROCAL, entre el Guabo, Balao y Ponce Enríquez principalmente, tal es el caso de Luz y Guía, Eloy Alfaro, Río Gala, Santa Martha, Nue- 
va Unión, Camilo Torres, San Miguel del Azuay. Comunidades campesinas heterogéneas que se vincularon en torno a los líderes políticos residentes en Shumiral, entonces, y hasta 1992, centro administrativo de la cooperativa. Hay que subrayar que los campesinos movilizados tuvieron recurrentes enfrentamientos con las autoridades locales y terratenientes al invadir directamente las haciendas y posesionarse como nuevos propietarios. Pero más allá de constituir este un proceso uniforme y avalado por el Instituto Ecuatoriano de Reforma Agraria y Colonización (IERAC), fue una lucha constante no del todo superada hasta los años noventa, puesto que en 1985, la UROCAL mantenía más del $80 \%$ de las tierras sin títulos de propiedad. ${ }^{10}$

La cooperativa continúo jalonando problemas de diversa índole. Tal vez el más complejo lo constituyó el proceso de conversión de un colectivo campesino originado en el conflicto por conseguir tierras, hacia una cooperativa cuyos fines debían tender a generar producción agrícola para su comercialización en el mercado; toda una novedad para la práctica totalidad de los campesinos de la zona que habían trabajado desde siempre bajo las órdenes del cacique en la plantación o como finqueros y aparceros. No se trataba únicamente de poner en marcha las tierras para el cultivo, de desmontar el bosque tropical y producir, sino de elaborar proyectos de gestión que fueron transformando las cooperativas en verdaderas empresas. ${ }^{11}$ Un proceso hilvanado con los proyectos de desarrollo implementados en el agro en las décadas subsiguientes al ciclo reformista, como fueron los programas de Desarrollo Rural Integral (DRI), entre otros.

UROCAL, aunque debió readecuar sus posiciones políticas, sobre todo a partir de los primeros proyectos de producción y comercialización de cacao y gestión de créditos, mantuvo una importante actividad social entre los campesinos de base; se impulsaban programas de educación, salud, formación agropecuaria, programas de tiendas comunales, bodegas de acopio, etc. En este senti-

10 Incluso títulos de tierras otorgados por el IERAC no tendrían el reconocimiento del Instituto Nacional de Desarrollo Agrario (INDA), entidad de derecho público adscrita al Ministerio de Agricultura y Ganadería, creado el 14 de junio de 1994, que vendría a sustituir al IERAC.

11 "Los líderes políticos de las organizaciones, convertidos, de pronto, en administradores de piladoras, secadoras y molinos, de cajas de crédito, de empresas de comercialización de insumos o pesando las cargas de cacao en calidad de inspectores de aquellos mismos que los eligieron. Midiendo el grado oculto de humedad del café de sus propios compañeros" (Ponce, 2004: 152-153). 
do, las relaciones mantenidas con diversas organizaciones sociales y sindicales a partir de la década de 1970, definieron un tipo de cooperativismo agrario muy particular. Destacó un grupo de voluntaristas españoles, conocido por entonces como "grupo Pucará", liderado en torno a la figura del cura ecuatoriano Hernán Rodas, cuya influencia carismática quedaría reflejada en los testimonios de los campesinos. ${ }^{12}$

Este cooperativismo agrario definido por las relaciones sociales mantenidas con movimientos activistas, se explicaba por una doble función; por un lado, la dinámica asociativa respondía a las nuevas demandas de la economía; los agricultores individualmente no podían acceder al mercado, la carencia de capital, infraestructuras, financiación, información sobre el funcionamiento de los mercados, etc., hacía inviables a las pequeñas economías campesinas. Juntos podían hacer frente a compras colectivas, sostener programas productivos abaratando costes en la compra de maquinaria, insumos, etc. Pero también se debía a un contexto político que recorría América Latina; si bien fue determinante la revolución cubana años atrás, durante la década del 70 se extendían movimientos sociales y religiosos relevantes por toda la región. La influencia de la teología de la liberación y las Comunidades Eclesiales de Base (CEB), supuso un revulsivo para aquellos pobres rurales condicionados por los poderes locales. ${ }^{13}$ En Ecuador las primeras comunidades cristianas de base se reunieron en agosto de 1975 en la provincia serrana de Chimborazo, y desde allí se fueron extendiendo por casi todo el país. Formadas por pequeños grupos de acción social, tomando la parroquia como entidad territorial representativa, las CEB llevaban a cabo funciones religiosas y sociales; entre estas últimas destacaban las reivindicaciones y acciones para mejorar la vida de las comunidades campesinas, paliar las condiciones de pobreza, fomentar trabajos colectivos, llevar a cabo programas de alfabetización, y participar en actividades sindicales y políticas. ${ }^{14}$

12 "Sí, una vez ganadas las tierras, aparece el padre Hernán Rodas, apareció el grupo Pucará [...], ellos fueron esenciales en la UROCAL y en su desarrollo; el CECCA liderado por el padre Hernán Rodas estuvo con nosotros por muchos años y su ayuda fue muy estimada". Entrevista a Jacinto Zambrano, tesorero de la UROCAL, agosto de 2010.

13 En buena medida, hasta las movilizaciones indígenas de la década de 1990 el poder local se había dirimido casi siempre a favor de los hacendados que tenían el control y autoridad sobre la tierra, con el resto de poderes locales tradicionales, es decir, la iglesia, representada por el cura y el teniente político.

14 A. D. CECCA (1985), "Comunidades Eclesiales de Base”, CECCA-CEDECO, Cuenca-Ecuador, pp. 
Estos grupos constituyeron una vertebración entre los campesinos de base y las instituciones estatales y privadas. No obstante, conviene subrayar que las organizaciones de segundo grado surgidas en la Costa, como en otras regiones, se limitaba, en buena medida, a la obtención de la propiedad de la tierra y de créditos para los cultivos. El cortoplacismo guiaba a numerosas cooperativas que por lo general "no sobrevivían de hecho a la distribución individual de las parcelas y del crédito agrícola cuando este no se podía recuperar". Así por ejemplo, según un estudio del CECCA, "las pocas organizaciones de segundo grado existentes en 1981, se debían a iniciativas frecuentemente rivales, tomadas por promotores y dirigentes más que por campesinos, y experimentaban también la inconstancia y los fracasos". Por tanto, se trataba de un asociacionismo debilitado por la práctica ausencia de programas estatales dirigidos al sector rural. Y de hecho cuando se llevaron a cabo programas de desarrollo compartían debilidades tanto en capital financiero, como en la lógica administrativa que los guiaban. Este fue, por ejemplo, el caso de FODERUMA, un subprograma del DRI, relativamente exitoso en UROCAL, debido fundamentalmente a la situación privilegiada que adquirió la cooperativa en el marco administrativo del programa dirigido por Hernán Rodas:

Una lección muy importante aprendida en los años 70 con FODERUMA, durante las primeras experiencias de créditos, partía de la racionalidad contableadministrativa de los burócratas en Quito versus racionalidad y funcionamiento campesino; y mi mayor gloria fue que los funcionarios de Quito vinieron a las tierras de los campesinos asociados a la UROCAL. Fue interesante su aprendizaje sobre la contabilidad campesina [...] mientras el banco te ponía líneas de crédito, nosotros dijimos no, sigamos la racionalidad campesina: "yo pido 1.000 USD y de estos pago una deuda que tenía, el otro pago un chancho, le doy a mi hija, pero termina el año y lo he devuelto todo". Es decir, se trataba de adecuar el lenguaje y la práctica a la lógica campesina. Porque si le dices al campesino: “este crédito para 'línea de trabajo', este otro para 'líneas de inversión”", esta racionalidad, generalmente chocaba con la campesina. En estos factores de orden antropológico estuvimos trabajando los responsables de FODERUMA. ${ }^{15}$ 
Pero FODERUMA representaba menos del 1\% de las operaciones del Banco Central del Ecuador (BCE) para 1979. Esto suponía un capital precario para los objetivos que planteaba el programa de desarrollo rural; por esto, y por una gestión en su conjunto deficitaria (nueve gerentes en nueve años, sin informes ni memorias evaluativas), FODERUMA tuvo un éxito escaso en el campo ecuatoriano.

La concesión de capital FODERUMA para proyectos tenía algunas condiciones, entre ellas, se otorgaba únicamente a los campesinos organizados, aunque lo fuesen solo de hecho, esto es, sin "legalizar". Las exigencias mínimas consistían en proponer un proyecto productivo que, más tarde sería evaluado por los técnicos de FODERUMA. Del monto total entregado por el BCE en el citado año se dirigió un 55\% a la actividad agrícola; $20 \%$ a la ganadería y un $25 \%$ a la artesanía, pesca y otras actividades no agrarias (De Janvri y Glikman, 1991: 359-360). Además, y esto era lo más interesante, del programa FODERUMA, un porcentaje equivalente al crédito dedicado a la actividad productiva era capital no reembolsable e iba dirigido a proyectos sociales. Se trataba de incorporar a las organizaciones campesinas a proyectos estatales de desarrollo rural; fomentar la construcción de carreteras, canales de riego, sistemas de agua tratada, letrinización, construcción de locales escolares, salud, nutrición infantil, capacitación agropecuaria y capacitación de mujeres. ${ }^{16}$ Programas que, evaluados por la organización CECCA años después, evidenciaban escasos logros, así como una serie de problemas constatados en toda la región de Latinoamérica: ${ }^{17}$ "la política estatal en torno a los DRI y FODERUMA ha pretendido estabilizar a los sectores en proceso de empobrecimiento, pero ha sido débil en medio de un proceso de rentabilidad productiva, por lo que ha promovido una vía de desarrollo campesino que contribuye a la expansión del capital". ${ }^{18}$

16 A. D. CECCA: "Proyecto de vivienda. Parroquia Ponce Enríquez-Shumiral”. Sistematización realizada por Iván González, abril de 1993.

17 Problemas estructurales entre los cuales sobresalían: los elevados costes para las economías dependientes, debilidad institucional y la fragilidad técnica y administrativa, así como el sempiterno problema distributivo (Portocarrero, 1985; Rojas López, 2008).

18 A. D. CECCA: "CECCA proceso organizativo y educativo en Salud". Sistematización realizada por Janeth Molina, mayo de 1992. 
La preeminencia del cultivo de cacao en la zona quedaba reflejada en los créditos concedidos por el programa FODERUMA y diversas entidades privadas de financiación. La UROCAL dedicó más del 50\% del monto obtenido al cultivo de esta planta, a la comercialización, mantenimiento de huertas y ampliación de las tierras de cultivo; así como la adquisición de terreno en Shumiral donde se ubicó una secadora de cacao. La participación directa de ONG, como Agro Acción Alemana y la Central Ecuatoriana de Servicios Agrícolas (CESA) en la consecución de este primer proyecto agrícola fue determinante. La secadora de cacao fue el punto de partida productivo de la cooperativa UROCAL:

En vez de bajar desde las alturas el cacao para trasladarlo con mulas, desde distancias grandes, para poder comercializarlo (algo que salía muy caro), se puso la secadora en el camino hacia Shumiral. Ese fue el punto de partida de la organización económica de Shumiral; en el sentido de que ya estaban asociados no solamente para defender su derecho a la tierra, su derecho al acceso al agua en el servicio domiciliar, sino para tener una iniciativa comercial asociativa. Entonces, todos venían a secar el cacao en la secadora, todos contribuían pagando lo que costaba para comprar el combustible. Y claro, todos ganaban más porque vendían a mejor precio. ${ }^{19}$

Para finales de los años 70 y principios de la década siguiente, la región de influencia de la UROCAL llegaba a cubrir un $60 \%$ de la población asociada en 32 organizaciones de base campesinas, fundamentalmente agrícolas. Se iban agregando asociaciones de jóvenes, de trabajadores pecuarios, comités femeninos, etc., dando como resultado una cooperativa de segundo grado heterogénea. Una parte importante de los campesinos tenían fincas dedicadas al cultivo de cacao; aunque entre 1976 y 1984 se iniciaba una actividad bananera ingente y dependiente de pequeños productores, especialmente en la provincia de El Oro. Sin duda, al margen de la diferenciación productiva emergente (camarón, minería, etc.), la agricultura seguía siendo el rubro principal que sostenía los hogares. Algunas unidades familiares dependían de ingresos subsidiarios adquiridos como trabajadores en haciendas colindantes; existiendo un $40 \%$ de población que formaba parte de la masa de jornaleros fijos e itinerantes en haciendas, e in-

19 Entrevista a la economista y activista social Betsy Salazar, Quito, 2010. 
cluso algunos pequeños comerciantes, cuyos productos iban dirigidos a cubrir las necesidades locales (Larrea, 1989; Larrea et al., 1988). ${ }^{20}$

\section{La contrarreforma agraria y la crisis del campesinado}

En 1979, con el triunfo del binomio Jaime Roldós Aguilera/Osvaldo Hurtado, se promulgó la Ley de Fomento y Desarrollo Agropecuario. Esta constituyó un marco jurídico protector de las medianas y grandes explotaciones en detrimento de las fincas de pequeño tamaño; dando prioridad al "proceso de colonización, la tecnificación de la producción agropecuaria y la represión de las tomas de tierras" (Rosero, 1988).

Bajo un contexto de crisis del cacao iniciado en 1981, sumado al impulso de las políticas neoliberales en la región, la vía campesina abierta por UROCAL, como por otras organizaciones, se cerraba parcialmente. Una nueva etapa alumbrada en la historia del país andino iba a expulsar del mercado laboral una ingente masa de agricultores que hasta este momento se habían ocupado de abastecer al mercado interno del país. El nuevo modelo de desarrollo de la década de 1980 vendría determinado por el incremento de las exportaciones y un deterioro del gasto público. La caída del precio del crudo en 1981 y el fracaso de los programas de Industrialización por Sustitución de Importaciones, darían lugar al fin del crecimiento sostenido de la economía ecuatoriana. Además, la deuda externa del país se acrecentaba y se buscó, como salida inmediata al equilibrio de la balanza del déficit, el fomento de la exportación. La contracción del gasto interno y la apertura comercial, definirían un periodo en la historia del país, hasta el siguiente auge petrolero en 2000, caracterizado por el empobrecimiento masivo y por la consolidación de las grandes compañías del sector extractivo y agroindustrial.

La pluriactividad en el sector rural y la estrecha relación con el nuevo mercado mundial de la alimentación, ligaban la producción agraria a las demandas

20 En la zona de influencia de Machala y por extensión en la provincia bananera de El Oro, la actividad camaronera permitió generar perspectivas de diferenciación productiva, ante una nueva situación que comenzaba a darse hacia 1984, cuando la Estándar Fruit y Noboa formalizan un conglomerado que, progresivamente, excluye a los pequeños productores. 
del mercado: triunfaba la agricultura de gran escala sostenida por los grandes patrimonios agroindustriales. Por ejemplo, en Azuay, mientras la producción de cereales y hortalizas iba reduciéndose entre las décadas del 70 y 80 , se ampliaron las hectáreas dedicadas al cultivo de la caña de azúcar, frutas para la industria, y por supuesto, cacao y café (tabla 1).

\section{Tabla 1}

Tendencias en la producción agrícola en la provincia del Azuay

\begin{tabular}{|l|c|c|}
\hline \multicolumn{1}{|c|}{ Productos } & hectáreas en $\mathbf{1 9 7 4}$ & hectáreas en 1980 \\
\hline Hortalizas & 1.800 & 1.600 \\
\hline Caña de azúcar & 17.700 & 19.500 \\
\hline Cacao, café & 4.030 & 7.500 \\
\hline
\end{tabular}

Fuente: el autor, a partir del A. H. CECCA

La proliferación de monocultivos, ampliando los tradicionales de cacao y banano a la palma africana y la caña de azúcar, iban cobrando importancia a partir de la década de 1970. Así por ejemplo, para el caso de los ingenios azucareros, se había pasado de una dedicación de 43.400 ha en 1974 a 107.700 ha en 1980, hasta iniciar el siglo XXI con 68.268 ha de este cultivo concentradas en Guayas, Cañar y Loja (Martínez Valle, 2011: 239).

Durante el invierno de 1982-1983 la corriente cálida de El Niño provocó inundaciones prácticamente en toda la costa del país. El Gobierno de Osvaldo Hurtado decretó el Estado de Emergencia en las provincias costeñas. Los daños ascendieron a 650 millones de dólares, con pérdidas importantes entre los sectores productivos, en torno al $63 \%$; un tercio en infraestructuras y los sectores sociales sufrieron pérdidas imponderables. El monto de tales daños originó efectos negativos en el crecimiento del PIB, una disminución importante de exportaciones, aumento del déficit fiscal y aumento de la inflación, entre otros, afectando al bienestar de amplios estratos de la población (MSP, s.f.). El Gobierno adoptó medidas propuestas por el Fondo Monetario Internacional cuyo impacto repercutió negativamente sobre la mayoría de la población; con la ex- 
cepción de los agroexportadores que tuvieron ciertos incentivos para renovar la producción perdida.

En ese mismo año la UROCAL celebraba su primer congreso en el recinto de Shumiral. En él se concretaban ideas y propuestas para ampliar y desarrollar las bases asociativas y productivas. En la zona de influencia de UROCAL, al igual que el resto de la Costa y desde los meses de octubre y noviembre de 1982, comenzaron a sentirse los efectos de un invierno adelantado que impidió la siembra. A partir de enero de 1983 las lluvias elevaron el caudal de los ríos Gala, Balao y Tenguel, que bajan por la falda montañosa de Mollepongo y desembocan en el océano Pacífico.

Fue un momento de crisis institucional para la UROCAL, cuando a partir del Fenómeno de El Niño de 1983 habíamos terminado nuestro primer congreso y vino este fenómeno que destruyó toda la región. Todo lo que habíamos acordado en el Congreso sobre políticas, ya no pudimos llevarlo a cabo porque la coyuntura cambió y tuvimos que pasar de una estrategia política a emergencia para atender a las personas. Fue todo un proceso de reconstrucción de la región, agrícola, poblados. ${ }^{21}$

En general, las pérdidas fueron cuantiosas en vidas humanas, infraestructuras, plantaciones y animales. Las plantaciones de cacao y banano se perdieron en su mayoría, se paralizó la producción de cacao; además se ahogaron numerosos animales y proliferaron enfermedades infecciosas como el carbunclo que contagiaba al resto de ganado.

La UROCAL dispuso una serie de comisiones de evaluación e intervención sobre los sectores afectados; se fueron fraguando comisiones de abastecimiento, salud, seguridad, vivienda, cuidado de niños, trabajos comunitarios, etc., con el objetivo de resolver una situación que convirtió la zona en catastrófica. Muchos campesinos abandonaron la agricultura para buscar oro en las brechas abiertas por las inundaciones en la falda de la cordillera de Mollepongo, en las estribaciones andinas de la provincia azuaya. Todo ello imprimió un giro inesperado en la cooperativa: las huertas habían quedado anegadas, poblaciones enteras devastadas, agricultores desencantados y desagregados de la organiza-

21 Entrevista a Joaquín Vásquez, Machala, 2010. 
ción vieron en la nueva actividad extractiva un "sueño dorado" que, como una pesadilla, agravó las desigualdades entre la población rural. Tanto niños como mujeres se dedicaron a estas actividades derivadas del trabajo extractivo. Para finales de la década de 1980 había más de 300 personas en el recinto de Shumiral, entre mujeres y niños, trabajando como tongueros y jancheros; de lo que se deduce la importancia que tuvo dicha actividad para la pequeña población.

\section{La agricultura agroecológica. Límites y potencialidades}

No cabía duda de que las aspiraciones de las organizaciones populares pasaban por inconvenientes institucionales y empresariales, pero también por coyunturas climáticas desfavorables. Las empresas dedicadas a la minería, así como las del banano, no eran escrupulosas con el territorio donde intervenían como enclaves, como tampoco lo fueron los campesinos que decidieron dedicarse a la actividad extractiva. Las instituciones gubernamentales actuaron bajo paliativos que conseguían reducir levemente las condiciones de precariedad de estas poblaciones rurales. El periodo caracterizado por las políticas de ajuste estructural, tal como hemos expuesto, no priorizaba entre sus programas políticas sociales públicas de amplia cobertura. Al contrario, como han mostrado varios estudios, el asistencialismo -por ejemplo, el "bono solidario" implantado en 1998 , en principio, como corrector ante el alza de precios- tenía presupuestado un capital para el año 2002 de 115 millones de dólares, cifra superior a la suma de las partidas dirigidas a salud, educación y vivienda, cuyo monto alcanzaba los 69 millones de dólares (Chiriboga y Wallis, 2010). De estos datos se inferían que las políticas sectoriales no alcanzaban los objetivos de elevar a niveles sostenibles la vida de los ecuatorianos y ecuatorianas. A todo ello, en 1994 se sancionaba un nuevo marco legislativo en el agro, la Ley de Desarrollo Agropecuario, bajo la presidencia del conservador Sixto Durán Ballén (19921996), una “contrarreforma agraria" (Martínez Valle, 2004: 25-40) que limitaba el papel de los pequeños campesinos y priorizaba la economía de mercado. Durante la década noventa se impulsaron los acuerdos regionales o mundiales de libre comercio: la Organización Mundial del Comercio se creaba en 1995, en las negociaciones de la Ronda de Uruguay (1986-1994), favoreciendo la li- 
beralización del comercio y la inversión de capitales a escala global. Se creaban tratados específicos en la región, tales como el Área de Libre Comercio de las Américas, Tratado de Libre Comercio de América del Norte, etc. (Moncayo, 1999).

Si bien la década de los noventa es la del reconocimiento político de las organizaciones indígenas, tras el levantamiento de 1990, supuso, también, el contrapunto organizativo, muy dirigido desde afuera por organizaciones internacionales del desarrollo. Un ejemplo podría ser la oferta de proyectos PRODEPINE (Proyecto de Desarrollo de los Pueblos Indígenas y Negros) puesto en marcha en 1998, cuyos efectos sobre la expansión organizacional en el sector rural fueron relevantes aunque insostenibles en el tiempo. Durante esta década los estudios sobre el sector rural se centraban obsesivamente sobre los movimientos indígenas, invisibilizando a los campesinos costeños sujetos a las dinámicas de la agricultura mercantil.

Durante el congreso celebrado por la cooperativa UROCAL en Shumiral en 1992, se percibían las corrientes una renovada revolución verde, o un intento de renovación, cuyos corolarios iban desde el desarrollo sostenible, a la agricultura ecológica y un largo etcétera de elementos conceptuales que, de una u otra manera, anunciaban cambios en las estrategias del desarrollo rural. Surgían nuevos marcos teóricos y analíticos para entender las transformaciones del mundo rural de los países latinoamericanos. La "nueva ruralidad", representación teórica de los cambios estructurales que, de hecho, se habían originado en las décadas pasadas, surgía a finales de los años 80 y se constituía en la base de muchos programas políticos y de gestión de la ruralidad.

A partir del citado congreso, la UROCAL iniciaba una serie de relaciones con organizaciones que fomentaban la agricultura orgánica. Un sistema de producción agrícola libre de insumos sintéticos y a partir de un tratamiento gradual y equilibrado del ecosistema. Pero a pesar de las legislaciones y discursos que abogaban por la seguridad alimentaria y el desarrollo sostenible, las prácticas agroecológicas no suponían más que del $2 \%$ de la producción global de alimentos, bajo precios que en ocasiones superaban el $50 \%$ de los convencionales. Además, diversos estudios constataban que los consumidores de productos orgánicos estaban menos interesados por cuestiones ecológicas que por la mejora 
de sus propias condiciones de salud, derivadas del consumo de esta producción orgánica (El-Hage y Hattam, 2003).

En el contexto nacional, la producción orgánica representaba, para datos de 2004, 31.793 ha de las cuales 4.076 estaban en proceso de certificación. El cultivo orgánico de fruta era liderado por el banano, seguido del cacao, café y palma africana. ${ }^{22}$ En 2007, Ecuador llegó a ser el mayor proveedor mundial, absorbiendo casi la mitad de las exportaciones mundiales, con más de 140.000 toneladas exportadas. Principalmente la fruta era destinada al mercado europeo (64\% aproximadamente) y alrededor de una tercera parte se exportaba a los Estados Unidos. Durante el período 2005 a 2007, el país triplicó sus exportaciones, debido a la obtención de nuevas tierras agrícolas certificadas. La producción orgánica de banano en Ecuador todavía representaba un tímido 3\% dentro del grueso de exportaciones en 2007. ${ }^{23}$

De esta manera, la UROCAL se sumaba a la producción agroecológica ${ }^{24}$, como una pequeña isla en medio de un mar de plantaciones de banano que inundaban toda la costa sur del país andino, desde Guayas hasta El Oro. La cooperativa iniciaba contactos, en los primeros años de la década de 1990, con el sistema denominado "comercio justo"25 europeo a través de la fundación Maquita Cushunchic Comercializando Como Hermanos (MCCH); una ONG que llevaba activa desde 1985 con sede en Quito:

Tenemos mucho que agradecer a Maquita por vincularnos a Holanda, allá por el año 1992-93; le debemos mucho, puesto que sin este primer contacto no habríamos logrado iniciar el camino agroecológico. En esta primera experiencia logramos dos objetivos básicos: el primero, iniciar la producción de banano orgánico e introducirlo en redes internacionales que estaban surgiendo entonces;

22 Datos de la Corporación de Promoción de Exportaciones e Inversiones-Ecuador (CORPEI, 2004) y UROCAL.

23 Datos de la FAO (2009: 22-23). Para 2010, la exportación de banano convencional era de 4’828.869,58 de toneladas métricas, según la Asociación de Exportadores de Banano del Ecuador (2010).

24 Como UROCAL, pero con menos trayectoria histórica, destaca la Asociación de Pequeños Productores Bananeros de El Guabo, en la provincia de El Oro: agricultores mancomunados entre 1994 y1997, que también operan en la Costa sur del país, manejando una agricultura orgánica.

25 El "comercio justo", impulsado por numerosas ONG, se remonta a la Primera Conferencia de la UNCTAD (Comercio y Desarrollo de las Naciones Unidas) celebrada en Ginebra, en 1964. 
segundo, fuimos madurando la idea de renovar huertas para producir cacao orgánico. Todo esto sumado a posteriores apoyos conformó la UROCAL actual. ${ }^{26}$

Estas relaciones mantenidas por la organización fueron decisivas para su inclusión dentro de las redes del "comercio justo", así como la definición de programas subsiguientes; el bagaje adquirido décadas pasadas y la preparación de los actuales promotores de la UROCAL fueron determinantes para su desarrollo en el litoral ecuatoriano. Una serie de vínculos establecidos con BanaFair, organización alemana de "comercio justo", los llevará a comercializar banano con diversas empresas mayoristas distribuidas por el territorio alemán.

UROCAL exportaba el cacao orgánico a países de la región como México donde agroindustrias como $\mathrm{AMCO}^{27}$ controlaban el comercio mundial de la fruta y su posterior puesta en el mercado mayorista; o bien hacia Estados Unidos y países europeos principalmente Suiza, Holanda y Francia. El cacao convencional se quedaba en el mercado nacional, siendo el Grupo Salinas uno de los principales receptores de la cosecha de la cooperativa. Realmente UROCAL comenzó a comercializar cacao orgánico en grano dirigido al mercado internacional en fechas recientes; en marzo de 2007 iniciaba, con algunas limitaciones, las exportaciones a Suiza. De esta manera, en febrero de 2008 había exportado 2.200 quintales de cacao en grano.

Como en décadas pasadas, se constataba la diferenciación social entre las familias asociadas. Desde la extensión de las fincas y su ubicación, disponibilidad de sistemas de irrigación, insumos técnicos e infraestructuras (empacadoras, vías de acceso, etc.), problemas con la certificación, capital inversor, entre otros, constituían los ejes problemáticos que atenazaban a estas economías campesinas. En la tabla 2 se puede observar la relación entre número de asociados, tipo de cultivo y hectáreas cultivadas.

26 Entrevista a David Romero, vicepresidente de la UROCAL, Puerto Inca-Guayas, agosto, 2010.

27 AMCO es el acrónimo de Agroindustrias Unidas del Cacao, con sede en México y filial de ECOM (Suiza), se trata de una transnacional de comercio mundial de productos básicos agrícolas, principalmente café, algodón y cacao. Según la información de ECOM, es uno de los tres principales comerciantes de café del mundo, así como uno de los mayores molinos de este producto. 
Tabla 2

Asociaciones de UROCAL: extensión y cultivos

\begin{tabular}{|c|c|c|c|c|}
\hline $\mathbf{N}^{\circ}$ & Asociación & $\begin{array}{l}\text { Hectáreas } \\
\text { de cacao }\end{array}$ & $\begin{array}{l}\text { Hectáreas } \\
\text { de banano }\end{array}$ & Socios \\
\hline 1 & Aso. Agrícola la Florida & 183,30 & 122,21 & 17 \\
\hline 2 & $\begin{array}{l}\text { Aso. Nuevo Porvenir } \\
\text { de El Oro }\end{array}$ & 100 & & 20 \\
\hline 3 & Aso. Agrícola Shumiral & 240 & & 24 \\
\hline 4 & $\begin{array}{l}\text { Aso. Productores } \\
12 \text { de Octubre }\end{array}$ & 85 & & 17 \\
\hline 5 & $\begin{array}{l}\text { Preasociación Prod. } \\
\text { Costa Azul }\end{array}$ & 54 & 36 & 18 \\
\hline 6 & $\begin{array}{l}\text { Aso. Productores } \\
\text { Nuevo Mundo }\end{array}$ & 213,45 & 853,80 & 102 \\
\hline 7 & $\begin{array}{l}\text { Aso. Mujeres Nueva } \\
\text { Esperanza Costa Azul }\end{array}$ & & & 11 \\
\hline 8 & Aso. Mujeres 3 de Junio & & & 23 \\
\hline 9 & Aso. Río Gala & 100 & & 20 \\
\hline 10 & Unión de Casacay & 320,20 & 35 & 59 \\
\hline \multirow[t]{2}{*}{11} & Aso. de mujeres Greta & & & 12 \\
\hline & Total & 869,05 & $1.047,01$ & 323 \\
\hline
\end{tabular}

Fuente: UROCAL, 2010

En suma, no siempre se hallaban las condiciones deseadas para el desarrollo de los asociados en su conjunto. La fragmentación de la tierra por herencia, la migración de los hijos, fuera y dentro del país, y el progresivo desencantamiento por el trabajo agrícola iban minando las expectativas de los pequeños agricultores. No obstante lo anterior, la cooperativa incrementaba las exportaciones 
de banano orgánico durante el periodo 2006-2011, con un promedio de 199.066 cajas anuales ofrecía, cuanto menos, cifras de exportación representativas para los pequeños productores asociados (tabla 3 ). Además, llevaba a cabo toda una serie de programas sociales que, como en décadas pasadas, definían una organización que había conjugado, unas veces con mayor éxito que otras, la producción y comercialización agrícola, con la sostenibilidad social y territorial.

Tabla 3

Banano orgánico exportado en el periodo 2006-2011

\begin{tabular}{|l|c|}
\hline Año & Cajas de banano orgánico \\
\hline 2006 & 208.696 \\
\hline 2007 & 189.292 \\
\hline 2008 & 206.915 \\
\hline 2009 & 187.900 \\
\hline 2010 & 187.003 \\
\hline 2011 & 244.425 \\
\hline 2012 (semana 40) & 169.230 \\
\hline
\end{tabular}

Fuente: UROCAL

De otro modo, las grandes empresas del banano se habían consolidado o estaban en proceso de hacerlo. Unos llevaban explotando el monocultivo desde las décadas de 1940-1950 y, o bien habían salido de país a tenor de las reformas agrarias y la crisis del banano, o adquirían nueva personería jurídica. Este era el caso, por ejemplo, de la transnacional Dole, anterior Standard Fruit Company, que operaba en el país desde 1955, el grupo UBESA, Unión de Bananeros Ecuatorianos, filial de Dole desde 1990, o los afiliados a la Asociación de Exportadores de Banano del Ecuador (AEBE), Grupo Noboa, Grupo Quirola o Reybanpac (Rey Banano del Pacifico), Grupo Wong. En cuanto a la situación laboral de los trabajadores en las grandes explotaciones se definían por la precariedad y flexibilidad. El incumplimiento reiterado del Código 
del Trabajo en relación a salarios, derecho a fondos de reserva, escasa o nula transparencia en los contratos y la permanente carencia de información sobre la relación contractual, etc. Era significativa la escasa representación sindical en las explotaciones agroindustriales: de los cincuenta sindicatos del Ecuador, tan solo quince pertenecían a grandes grupos empresariales; un déficit en la organización de trabajadores representativo de la escasa movilidad que deprimía las condiciones laborales de estos asalariados (SIPAE, 2011).

Según el Censo Agropecuario 2001, las tierras dedicadas al cultivo bananero estaban en propiedad, fundamentalmente, de tres patrimonios agroindustriales: Grupo Noboa, Grupo Quirola y Grupo Wong (tabla 4).

Tabla 4

Concentración de tierras en el agronegocio del banano

\begin{tabular}{|l|c|c|}
\hline Agroindustria & Superficie (hectáreas) & Cabezas de ganado \\
\hline Grupo Noboa & 19.184 & 4.316 \\
\hline Grupo Quirola & 17.199 & 4.449 \\
\hline Grupo Wong & 4.105 & 3.550 \\
\hline
\end{tabular}

Fuente: III Censo Nacional Agropecuario, 2001

Para cambiar las condiciones negativas de la producción bananera, el Estado ecuatoriano impulsa recientemente la reducción de la superficie cultivada sustituyendo las plantaciones por otras cuya producción derive mayor valor agregado: bosques o plantaciones de interés industrial, como el cultivo de plantas de fibras para textiles o para embalajes. También se estudian elementos de estímulo para impulsar a medianos y pequeños productores para que se decidan a sustituir la producción del monocultivo de bananos por otras especies redituables que permitan superar la explotación de seres humanos, evitar la depredación ambiental y controlar la concentración desmesurada de riqueza en pocas manos. 


\section{Conclusiones y reflexiones}

Tello se preguntaba para el caso de las agriculturas mediterráneas, si era realmente necesario haberlo hecho tan mal, una cuestión que subyacía de la constatación de que en el pasado "las sociedades agrarias organizaron los usos del territorio con distintos gradientes de intensidad, y siempre de forma sumamente integrada, porque de ello dependía su propia subsistencia [...] la gente no solo vivía en un territorio sino básicamente del territorio que habitaba" (Tello, 2010: 379ss). A lo largo del último medio siglo abarcado en esta investigación se han constatado evidencias que deberán reevaluarse así como considerarse para redefinir las estrategias de supervivencia del mundo rural ecuatoriano.

El ciclo reformista agrario de las décadas del 60 y 70 tiene sus antecedentes inmediatos entre los años 1934 y 1948. Esto es, entre el asentamiento de enclaves bananeros en la Costa, especialmente la United Fruit Company, y el boom económico propiciado por esta fruta tropical. Las reformas agrarias fueron palanca de emancipación y contexto de lucha política; dieron legalidad parcial a asentamientos de colonos que años antes se habían consolidado en el litoral. Algunos campesinos obtuvieron tierras a partir de la acción colectiva y la sindicalización; pero en buena medida, la carencia de crédito e insumos requeridos para la permanente modernización de las fincas en el marco de la revolución verde, provocaría la pérdida de las tierras obtenidas. Así, de campesinos aparceros, pasarían por un breve lapso temporal a ser propietarios, para después engrosar, progresivamente, las filas del trabajador rural bajo condiciones salariales y laborales precarias y siempre eventuales.

Los programas de modernización rural implementados a partir de la década del 80 y sobre todo 90, fueron abandonando el tema de la reforma agraria; abordando el sector rural desde programas de compensación social. Entre la política doméstica, las instituciones financieras internacionales y los acuerdos de libre comercio, en el marco de la economía de mercado, el papel de los pequeños agricultores iba deprimiéndose. En esta década del 80 la pobreza se volvió estructural en el campo ecuatoriano y las emigraciones fueron una constante.

En otro orden, se constata la necesaria dialéctica entre los actores implicados en el desarrollo rural: las organizaciones públicas y privadas, los agricultores y en general las organizaciones populares. De esta manera se puede 
promover un desarrollo endógeno y sostenido en el tiempo, no por ello exento de problemas. En este punto la investigación pone de relieve los claroscuros de las instituciones del desarrollo. Nada nuevo si pensamos en la modernización que desde el siglo XIX viene errando en la adquisición de modelos de desarrollo ajenos a las comunidades campesinas e indígenas. Cabe señalar las controversias y contingencias de la teoría de la modernización y la teoría de la dependencia, como representantes de dos manifestaciones opuestas, aunque con pretensiones de resolver los problemas sociales de la región, o al menos comprenderlos. Amerita seguir explorando estas corrientes, como otras propuestas analíticas en claro lineamiento con los movimientos sociales y alternativos, demandantes de una democracia participativa. Asunto nada baladí, si consideramos el papel que juegan los actores sociales en las administraciones locales, como ejes territoriales básicos del desarrollo de la comunidad.

También se evidencia la diversidad de los agricultores del litoral, como consecuencia de la tenencia de tierra, el acceso al agua y a los sistemas de irrigación, el tipo de cultivo, la disposición de infraestructuras, la localización geográfica de la finca, el acceso a los mercados y a los flujos de información. Todo ello, pone de relieve la complejidad y diversidad del mundo rural y la problemática permanente a la que se halla sometido el agricultor ecuatoriano.

La agricultura orgánica y el denominado "comercio justo", ${ }^{28}$ propuestas alternativas a la agricultura industrial y al libre comercio, están seriamente afectadas por una serie de problemas, para el caso investigado y que afecta a muchas otras organizaciones campesinas en la Costa, causados por la incursión de los grandes patrimonios bananeros en dichas alternativas productivas y comerciales, en origen creadas para las pequeñas economías campesinas. Como además se establecen disyuntivas entre producir más o sostener el territorio desde el punto vista ecológico.

28 Existen diferencias entre producción orgánica y producción dirigida al "comercio justo"; el primer tipo de producción no tiene por qué ser exportada a través de las redes de comercio alternativo, y el segundo, no hay que asimilarla mecánicamente a un producto orgánico. Por otro lado, los beneficios de los bananos de "comercio justo" se basan en el sistema de FLO International, que garantiza un precio mínimo y además paga una prima. El precio mínimo dependerá del país de origen y de si la fruta es orgánica o no (FAO, 2009). 
La asociación entre los agricultores fue determinante a lo largo del periodo histórico investigado, como lo continúa siendo actualmente. Sin un mínimo de mancomunidad el agricultor costeño no tiene posibilidades de reproducirse en el agro ecuatoriano. Asimismo, la supervivencia del agricultor depende en buena medida, como hemos reiterado, del acceso al recurso tierra y agua, y en el caso particular de los pequeños productores de banano, para que la producción sea rentable se requiere una extensión mínima de cultivo de entre 10 y 15 hectáreas. Un acceso a la tierra que muy pocos campesinos tienen en la zona de estudio, debido al acaparamiento del recurso ejercido por los agronegocios, la expansión del minifundio, entre otros problemas subrayados. Además, las estrategias del capital son sutiles, y en el caso de los patrimonios del banano, más que concentración de tierra se detecta una diversificación de capital y control de la cadena productiva, a través de inversiones en multipropiedades y negocios subsidiarios de la agricultura, como la elaboración de cartón para las cajas del banano, insumos químicos o infraestructuras.

Los pequeños productores representan una alternativa a la dirección del desarrollo rural tomado desde las últimas décadas bajo la permanente sombra de la economía de mercado. La complejidad del mundo rural del país, imbricado en la economía global, ofrece un semblante crítico para las pequeñas economías agrícolas. No obstante, las reformas constitucionales llevadas a cabo por el Gobierno de Correa a partir de 2008 podrían representar un cambio en la dirección del país. Representativos de los cambios aducidos, han sido, entre otros apuntados en estas líneas, los recientes programas implementados por el Gobierno de Alianza País, y desarrollados desde el MAGAP (Ministerio de Agricultura, Ganadería, Acuacultura y Pesca). Destaca la Ley de Tierras, que según el propio documento ministerial debe llevar a cabo un programa "encargado de la redistribución de las tierras en el marco de una verdadera Revolución Agraria". De esta manera, en marzo de 2013 se habían adjudicado un total de 20.524 hectáreas, beneficiando a 4.020 familias del Ecuador (MAGAP, 2013). Un programa complementario a la adjudicación de tierras es el denominado "Redes comerciales"; cuyos objetivos pasaban por impulsar las redes de comercio de pequeña y mediana escala dotando a las organizaciones campesinas de asesoramiento técnico, capacitación tecnológica, y la "recuperación de saberes 
ancestrales, así como desarrollar estrategias para promover el consumo social y ambientalmente responsable" (MAGAP, 2013).

No existe un modelo ideal de desarrollo rural, como no se trata de idealizar la agricultura orgánica practicada por la cooperativa objeto de estudio, cuyas divergencias y asimetrías, así como sus logros y potencialidades se han evidenciado históricamente; sino someter a un análisis crítico el proceso de producción agroalimentario global surgido a partir de la revolución verde, como parte de un problema estructural que afecta, no solo a los pequeños campesinos locales, por otro lado, arquitectos históricos de la seguridad alimentaria, sino en definitiva al sostenimiento ecológico y por tanto social de las generaciones futuras. El debate, pues, no es únicamente económico, sino profundamente político e histórico.

\section{Bibliografía}

Barsky, O.

1984 La reforma agraria ecuatoriana.

Carrillo García, G.

2013 "Historia agraria y organización social en la Costa austral de Ecuador, 19502010. Estudio de caso de una cooperativa agrícola: La Unión Regional de Organizaciones Campesinas del Litoral, UROCAL". Tesis doctoral. Facultad de Letras de la Universidad de Murcia. España.

Chiriboga, M.

2010 “Dinámicas territoriales rurales en América Latina”. En: Revista Eutopía. $\mathrm{N}^{\circ}$ 1, noviembre de 2010, pp. 51-68.

Chiriboga, M. (ed.)

1988 El problema agrario en el Ecuador. ILDIS: Quito.

Chiriboga, M. y Piccino, R.

1981 La producción campesina cacaotera: problemas y perspectivas, Centro de Arte y Acción Popular (CAAP)/Centro de Educación y Capacitación del Campesino del Azuay (CECCA). No 6. Quito-Ecuador.

Chiriboga, M. y Wallis, B.

2010 "Diagnóstico de la pobreza rural en Ecuador y respuestas de política pública”. RIMISP, noviembre de 2010. 
Cueva, A. et al.

1983 Ecuador: pasado y presente. Quito: Instituto de Investigaciones Económicas.

De Janvri, A. y Glikman, P.

1991 Encadenamientos de producción en la economía campesina en el Ecuador. San José: Fondo Internacional de Desarrollo Agrícola (FIDA).

El-Hage Scialabba, N. y Hattam, C. (eds.)

2003 Agricultura orgánica, ambiente y seguridad alimentaria. FAO.

\section{FAO}

2009 La certificación en las cadenas de valor en las frutas frescas. El ejemplo de la industria del banano, Roma.

Giarracca, N. (comp.)

2001 ¿Una nueva ruralidad en América Latina?, Buenos Aires: CLACSO.

Griffin, K.

1974 The Political Economy of Agrarian Change. An essay on the Green Revolution. Londres: Macmillan Press.

Guerrero, A.

1979 "La formación del capital industrial en la provincia de Guayas, 1900-1925". En: Revista Ciencias Sociales. Vol. III. No 10-11. Quito.

Hobsbawm, E.

1998 Historia del siglo XX. Buenos Aires: Crítica.

Humbert, De Grammont

2004 "La nueva ruralidad en América Latina". En: Revista Mexicana de Sociología. Universidad Nacional Autónoma de México/Instituto de Investigaciones Sociales. Año 66. Número especial. México D. F., pp. 279-300.

Ibarra, $\mathrm{H}$.

2010[1979] "Movilización y organización campesina en la costa ecuatoriana

Jordán, F.

(1950-1962)". CAAP. No 80. Quito, pp. 137-148.

2003 "Reforma Agraria en Ecuador". En: Vargas Vega, John D. (coord.). Proceso agrario en Bolivia y América Latina. La Paz: Plural Editores.

Larrea, C.

1989 “Agroexportación y estructura social en Machala: 1948-1984”. S/e.

Larrea, C. et al.

1988 "Agroexportación, transnacionales y paisaje agrario en la costa ecuatoriana”. En: Gondard, P. et al. Transformaciones agrarias en el Ecuador. IPGHORSTOM, Quito, pp. 71-94. 
Marchena Fernández, J.

2006 "La voz de los cerros y los páramos. Los universos indígenas andinos en su lucha por la educación y el respeto de sus identidades". En: Revista Historia de la Ecuación Colombiana. № 9, pp. 9-71.

Martínez Valle, L.

2006 "Las organizaciones de segundo grado como nuevas formas de organización de la población rural". En: Grammont, H. C. La construcción de la democracia en el campo latinoamericano. Buenos Aires: CLACSO.

Martínez Valle, L.

2004 "El campesino andino y la globalización a fines de siglo (una mirada sobre el caso ecuatoriano)". En: Revista Europea de Estudios Latinoamericanos y del Caribe. $N^{o}$ 77. CEDLA: Centro de Estudios y Documentación Latinoamericanos. Ámsterdam, octubre de 2004, pp. 25-40.

Martínez Valle, L.

2003 Dinámicas rurales en el subtrópico. El caso de La Maná. Quito: CAAP.

Martínez Valle, L. (comp.)

2000 Antología de estudios rurales. Quito: FLACSO-Ecuador.

Martínez Valle, L.

1976 Auge y crisis del banano en la provincia de Esmeraldas. Quito: Instituto de Investigaciones Económicas de la Universidad Central del Ecuador.

Martínez Valle, L. y Grammont, H. (comp.)

2009 La pluriactividad en el campo latinoamericano. Quito: FLACSO-Ecuador.

MSP del Ecuador

s/f. "Informe sobre el fenómeno El Niño en Ecuador".

Ojeda Segovia, L.

2000 La descentralización en el Ecuador. Avatares de un proceso inconcluso. Quito: Abya-Yala.

Moncayo, E.

1999 Las relaciones externas de la comunidad andina. Entre la globalización y el regionalismo abierto. Lima: Secretaría general de la Comunidad Andina.

Pachano, S.

1988 "Transformación de la estructura agraria: personajes, autores y escenarios". Picado, W. En: Chiriboga, M. (ed.) El problema agrario en el Ecuador. Quito: ILDIS.

2012 "En busca de la genética guerrera. Segunda Guerra Mundial, cooperación agrícola y revolución verde en la agricultura de Costa Rica”. En: Revista Historia Agraria. № 56, pp. 107-134. 
Ponce, J.

2006 La apuesta campesina por la agroecología. Los productores bananeros están en el comercio justo. Quito: BanaFair, CEP, UROCAL.

Ponce, J.

2004 Sentado entre dos sillas. Historias de un malpensante sobre la cooperación al desarrollo. Quito: Planeta.

Portocarrero, B.

1985 El capitalismo dependiente y su incidencia en el problema agrario venezolano. Valencia: Vadell Hermanos Editores.

Rojas López, J.

2008) "La agenda territorial del desarrollo rural en América Latina". En: Observatorio de la Economía Latinoamericana. № 96, abril de 2008.

Salgado Gómez, M.

2008 "Galo Plaza Lasso: la posibilidad de leer el paradigma desarrollista desde una apropiación reflexiva”. En: De La Torre, C. y Salgado, M. Galo Plaza y su época. Quito: FLACSO-Ecuador.

Silverman, M.

1986 "Variabilidad agraria en la Costa ecuatoriana". En: Murmis, M. (ed.). Clase y región en el agro ecuatoriano. Quito: Corporación Editora Nacional, pp. 79-174.

SIPAE

2011 "Prácticas de compra y condiciones sociales, laborales y ambientales en las plantaciones bananeras ecuatorianas que exportan a Alemania”. Quito: SIPAE.

Striffler, S.

2002 In the shadows of state and capital. The United Fruit Company, popular struggle, and agrarian restructuring in Ecuador, 1900-1995. Durham \& London: Duke University Press.

Striffler, S.

2000 "Clase, género e identidad: la United Fruit Company, Hacienda Tenguel y la reestructuración de la industria del banano". En: Revista Ecuador Debate. Quito: CAAP, pp.155-178.

Tello, E.

2010 "Un vínculo perdido: energía y uso del territorio en la transformación histórica de los paisajes agrarios mediterráneos". En: Garrabou, R. Sombras del progreso. La huella de la historia agraria. Barcelona: Crítica, pp.353-382. 
Thompson, E.

1995 Costumbres en común. Barcelona: Crítica.

Uggen, J.

1975 Peasant mobilization in Ecuador. A case study of Guayas province, Ph. D. dissertation. University of Miami.

\section{Entrevistas para este artículo}

Joaquín Vásquez, Madrid, 2009; Machala, El Oro, 2010.

Betsy Salazar, economistas y activista social, Quito, 2010.

David Romero, vicepresidente de la UROCAL, Puerto Inca-Guayas, 2010.

Jhonny Yansaguano, finca El Rosario, Balao.

Hernán Rodas, Paute, Azuay, 2010.

Jacinto Zambrano, tesorero de la UROCAL, Shumiral, 2010.

Envío 01 de octubre/2013 - Aceptación 17 de diciembre/2013 